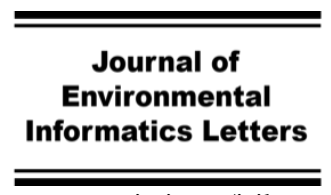

www.iseis.org/jeil

\title{
Examining an Oil Spill Plume Mapping Method based on Satellite NIR Data
}

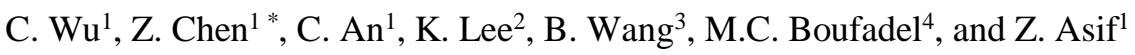 \\ ${ }^{1}$ Department of Building, Civil, and Environmental Engineering, Concordia University, Montreal H3G 1M8, Canada \\ ${ }^{2}$ Ecosystem Science, Fisheries and Oceans Canada, 200 Kent Street, Ottawa K1C OE6, Canada \\ ${ }^{3}$ Hyperspectral Remote Sensing Engineering Research Center for Ecological Environment Monitoring, Yangtze Normal University, \\ Chongqing, 408100, China \\ ${ }^{4}$ Center for Natural Resources, Department of Civil and Environmental Engineering, Newark College of Engineering, New Jersey Institute of \\ Technology, Newark NJ 07102, USA
}

Received 19 November 2020; revised 19 December 2020; accepted 20 January 2021; published online 04 April 2021

\begin{abstract}
Reliable information on the spreading of oil plume on water caused by massive oil spills is essential for making proper clean-up measures. Satellite remote sensing technology has advantages over other methods in terms of larger coverage and without expensive operating costs to detect oil spills. In this study, an oil plume delineation method based on the Near-Infrared (NIR) satellite data is used to examine oil spill plume area and size for the BP Deepwater Horizon Oil Spill in the offshore water of Gulf of Mexico and for the recent Norilsk oil spill in a Northern inland water region. To get accurate results noise signals such as land from the data are masked out using SNAP based DEM data and Normalized Difference Water Index method, whereas cloud signals are removed using MODIS cloud masking. Cox-Munk model is used to compute the sun glint radiance. Results of DP oil spill case depicts a $4838.84 \mathrm{~km}^{2}$ thicker oil plume along with the $20635.53 \mathrm{~km}^{2}$ thinner portion of the oil slicks using MODIS NIR data at a 500-meter resolution. It is subsequently applied to the recent Norilsk Oil Spill using higher resolution Sentinel-2 NIR data to test the method for detecting spill plume in an inland river water system. Reasonable high-resolution results at 10 meter have been obtained for the smaller scale oil spill onto river water compared to larger offshore area, considering that the river site has complex conditions including shallow water and river reddish soil close to oil color. The developed method is suitable for detecting thick oil plume in ocean or deep inland water bodies.
\end{abstract}

Keywords: oil spill plume, near-infrared, open water, MODIS, Sentinel-2, satellite, remote sensing

\section{Introduction}

Oil pollution entering the ecosystem has been an issue of concern for many years and occur for various reasons. In the marine ecosystem, the leading sources of oil spills are operative discharge of ships, accidents on ships, accidents relating to oil drilling platforms, etc., (Lee et al., 2016). Whereas, for inland water systems, oil spills may come from pipelines leakages (Nielson et al., 2020) or failures of oil tanks (National Public Radio, Inc., 2020). These oil spills can lead to severe damage to aquatic life, habitat destruction, imperiling local flora, and fauna as well as human activities (Krestenitis et al., 2019).

To reduce the adverse impacts of oil spills on the environment, and to support the immediate remediation decisionmaking, accurate oil plume mapping is often required (Liu et al., 2017; Fingas and Brown, 2018). Precise source identification and oil spill monitor can be conducted through ship or aircraft surveillance, but these methods may be constrained by time delays and narrower spatial coverage (Lee et al., 2016).

* Corresponding author. Tel.: + (1) 5148482424 ext. 8775 .

E-mail address: zhi.chen@concordia.ca (Z. Chen).

ISSN: 2663-6859 print/2663-6867 online

(C) 2021 ISEIS All rights reserved. 10.3808/jeil.202100050
Satellite remote sensing, on the other hand, is often applied for oil plume delineation due to its shorter revisit time and wider spatial coverage (Gede Putra et al., 2015; Liu et al., 2017). Datasets from a variety of satellites have been employed for mapping oil plumes. For example, synthetic aperture radar (SAR) is capable of detecting the returned signals reflected by small capillary waves, these waves can be dampened by oil plume layers and reduce the returned signals to the SAR sensors resulting in darker areas in the image (Arslan, 2018). Garcia-Pineda et al. (2009) used data from RADARSAT-1 (one SAR sensor) and employed a texture-classifying neural network algorithm (TCNNA) to achieve a good performance in oil slick extraction. Though SAR sensors have the advantage of operating under all-weather condition, look-alikes (biogenic films, algae, etc.) cannot be distinguished and the SAR based approaches are limited to wind speed ranging from $3 \mathrm{~m} / \mathrm{s}$ to $10 \mathrm{~m} / \mathrm{s}$ (Pisano et al., 2015; Arslan, 2018).

Optical sensors, on the other hand, may be affected by clouds but has the capacity to identify look-alike oil slicks through the sensed optical information (Arslan, 2018). Gede Putra et al. (2015) estimated the Fluorescent index from MODIS data in the Timor Sea and successfully estimated the oil covered area. Bulgarelli and Djavidnia (2012) characterized the difference between the spectral properties of suspected oil and that of the surround- 
ing sea water under the absence of sunglint, using MODIS data in Gulf of Mexico in 2010. Althawadi and Hashim (2019) extracted oil spill information in Arabian Gulf from Sentinel-2 image using the RGB (red, green and blue) bands and a regionbased segmentation method. Kolokoussis and Karathanassi (2018) also managed to identify oil plumes in the South coast of Athens, Greece using Sentinel-2 data. Herein, data from the Moderate Resolution Imaging Spectroradiometer (MODIS) and Sentinel-2 are being explored to delineate oil plumes.

In past studies, different spectrums have been applied to detect the signal contrast of different optical characteristics between oil plume and the surface water in marine environments but scarcely in inland water systems. The optical contrast between oil and the surrounding water may be affected by oil type, oil evaporation degree, weather condition and sun illumination (Fingas and Brown, 2018). However, remote sensing technology can identify oil and water based on their spectral absorption and scattering properties.In the near infrared (NIR) range, water has strong absorption rate and negligible scattering, while crude oil has a strong absorption rate in the short wavelengths but considered exponentially weaker with longer wavelengths (Sun and Hu, 2019). Clark et al. (2010) points out that the reflectance of emulsions formed by thick oil with water and other matters in the ocean is larger than the reflectance of water in the NIR spectrum range. It is usually observed that both crude oil and emulsified oil have a higher reflectance rate than water in the NIR range, making the detection of oil possible in this spectrum.

The aim of this study is to develop an oil plume delineation method for detecting oil spill plume in both offshore and inland water areas based on satellite remote sensing information in the NIR range. Particularly, the marine-viable method is modified for monitoring oil spill in an inland water system. The developed approach is applied to two different cases, one based on the Deepwater Horizon Oil Spill onto the offshore water of Gulf of Mexico (GOM) and another is the inland oil spill onto a river basin in Northern Russia.

\section{Methodology}

Satellite remote sensing has been long adopted for the estimation of water components in inland water bodies that absorb or scatter color presenting watercolor, referred as optically active waterbody constituents (OAC), those water components include Chlorophyll-a (Chla), total suspended solids (TSS), and colored dissolved organic matter (CDOM) (Topp et al., 2020). The concept can be explored to differentiate oil color and the surrounding water color possibly for oil spill detection in inland waters. Satellite images usually contain noise signals (e.g., land, cloud) especially for inland water systems due to the smaller areas in inland water region compared to vast marine environment. Noise signals, not related to oil and water, need to be removed prior to the analysis of oil plumes on the sea and rivers (Lee et al., 2016). It is challenging that these noise signals such as land soil may have the same reflectance level as oil, leading to misidentification of oil plumes.

In remote sensing images, water in the glinted areas can easily be misidentified as oil (Fingas and Brown, 2018). In the GOM case, oil in the non-glinted area may have the same reflectance as water in the glinted area. Several models, including the Cox-Munk model (Cox and Munk, 1954), Shaw-Churnside model (Shaw and Chumside, 1997), Wu model (Wu, 1972), Mermelstein model (Mermelstein et al., 1994) are available for accessing the sun glint radiance. It is found that among these models, the Cox-Munk model performs the best, which is used in this study (Zhang and Wang, 2010).

Figure 1 presents the main framework to quantify the area of oil plume over water based on the analysis of NIR data. The proposed approach includes data pre-treatment steps to remove noise signals from each satellite image, including land masking, cloud masking, glint level calculation, and the main NIR based oil mapping step. Software used in this study are the Sentinel Application Platform (SNAP) from the European Space Agency (https://step.esa.int/main/toolboxes/snap/), along with SeaDAS toolbox (https://seadas.gsfc.nasa.gov/installers/sanpseadas-toolbox/) and MATLAB. Details are discussed in the following sections.

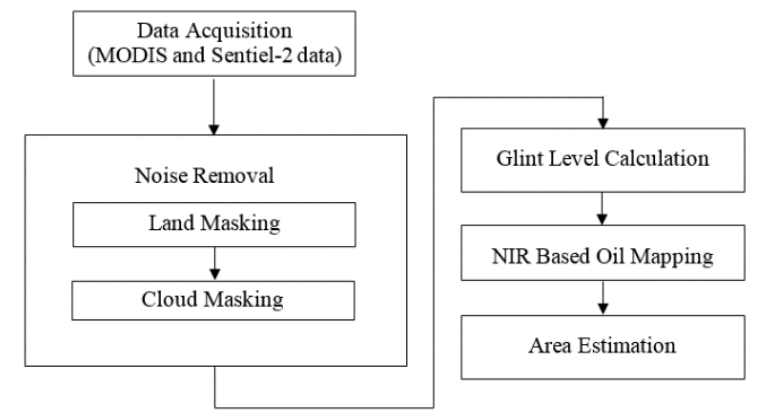

Figure 1. The framework with main steps for the proposed oil mapping method.

\subsection{Land and Cloud Masking}

The first step after data acquisition is to remove the noise signals for better analysis. Satellite images may contain signals that are not desired for analysis, including land (Lee et al., 2016) and clouds (Liu et al., 2017). In some cases, signals from land and clouds may have the same reflectance level as signals from the water surface, leading to misidentification of oil plumes. For this reason, it is important to mask out noise pixels before the analysis process. Land pixels from offshore marine environments can be masked out using SNAP based on the SRTM-3 sec (Shuttle Radar Topography Mission launched in 2009) using digital elevation model (DEM) data.

The method used for offshore land masking is not applicable to the removal of land pixels from inland water systems as the elevation of these systems can be larger than $0 \mathrm{~m}$. Therefore, the Normalized Difference Water Index (NDWI) is calculated for each pixel using the following equation (Du et al., 2016):

$N D W I=\frac{\rho_{3}-\rho_{8}}{\rho_{3}+\rho_{8}}$ 
where, $\rho_{3}$ and $\rho_{8}$ are the top of atmosphere (TOA) reflectance of the green band (band 3) and the NIR band (band 8) from Sentinel-2, both two bands have a spatial resolution of $10 \mathrm{~m}$. The NDWI is also applied for offshore water area for additional land pixel removal.

Characteristics of water at different time and location may vary and require specific thresholds for better water extraction (Du et al., 2016). It is found that the optimized NDWI threshold can provide better results with more accuracy than the standard threshold (Acharya et al., 2018). In cases that have insufficient ground truth data, thresholds are selected with the narrowest boundaries around the water bodies to minimize the misidentification of oil plumes from water caused by thin water layers, poor water quality or other affecting factors. Clouds can be removed from the data which are flagged as clouds based on the MODIS cloud mask product (Roger et al, 2015).

\subsection{Glint Level Calculation}

After the removal of noise signals, unequal reflectance in glinted area and non-glinted area should be then dealt with. When an oil plume is in a glinted area like the GOM oil spill area, the site area may reveal a high reflectance from water in the glinted area with similar reflectance values from oil in the less-glinted area. Therefore, it is important to calculate the glint levels of each pixel. Several models can be used to estimate the sun glint radiance, among which the Cox-Munk model is selected in this study (Cox and Munk, 1954; Zhang and Wang, 2010). The normalized sun glint radiance based on isotropic version (independent of wind direction) of the Cox-Munk model can be computed (Pisano et al, 2015):

$L_{G N}=\frac{r(\omega) P(\beta, \sigma)}{4 \cos \theta_{0} \cos \theta \cos ^{4} \beta}$

where $r(\omega)$ is the Fresnel reflection coefficient of the specular reflection angle $\omega ; P(\beta, \sigma)$ is the probability distribution of sea surface facet slopes relating to the zenith angle $\beta$ of each facet and the isotropic sea surface slope coefficient $\sigma$ depending on the local wind velocity. $\theta_{0}$ and $\theta$ represent the solar zenith angle and the sensor zenith angle, respectively.

This method is used to calculate the sun glint radiance based on the corresponding MODIS data. Given that the same type of pixels has a similar range of reflectance level in a certain range of solar glint radiance, oil and water can then be distinguished in that solar glint radiance range, the extracted water area can be divided into different zones based on their own glint level.

\subsection{NIR Based Estimation of the Water Oil Plume Size}

After the above discussed preprocessing of satellite data, the oil mapping can be undertaken. Thick oil often forms emulsions with water and other matters in the ocean. Past laboratory experiments showed that the reflectance of oil emulsions has a greater reflectance as compared to water in the NIR range (Clark et al., 2010). As oil and water have different spectral absorption and scattering properties in this range, a single threshold is ex- amined to separate water and oil pixels for oil plume delineation. For instance, Band $2(\lambda=859 \mathrm{~nm})$ of MODIS and Band 8 $(\lambda=842 \mathrm{~nm})$ of Sentinel-2 are examined to estimate the area size of oil spill plume as these two bands are the NIR bands with the finest spatial resolution of their satellites and the band center of these two bands are close. Threshold values for each glint level area are determined based on the analysis of the oil plume shape in that area and the total oil covered area, which can be crossed-compared with the reference data. When there is no reference data, the largest reflectance value in the middle of the oil-free water area can be examined as the threshold value.

\section{Results and Discussion}

\subsection{Case 1: GOM Deepwater Horizon Oil Spill}

The first case selected in this study is the Deepwater Horizon Oil Spill that occurred in the Gulf of Mexico on April 20th, 2010. The oil spill originates at around $28^{\circ} 44^{\prime} 17.30^{\prime \prime} \mathrm{N} 88^{\circ} 21^{\prime}$ $57.40^{\prime}$ W (Figure 2(a)) due to the failure of the Deepwater Horizon drilling rig, causing 3.19 million barrels of crude oil being continuously leaked into the ocean for three months (Sun and $\mathrm{Hu}, 2019$ ). MODIS surface reflectance data MOD09GA products on May 17th, 2010 (data source: https://search.earth data.nasa.gov) is extracted to build the model. The corresponding RGB image is obtained in Figure 2(b).

\subsubsection{Results of the Satellite Derivation}

The satellite-derived results of the detected oil plume size or area and plume geometry shape in this study is compared to the ground truth or reference data. As introduced in Section 2, the method in the present study uses band 2 MODIS NIR data and with threshold mechanisms to reduce noise for accurately detecting oil plume size and plume geometry. The proposed method is here tested by applying to the GOM offshore oil spill case. Literature methods and reference data for the GOM case is employed to examine results of the proposed method. Clark et al. (2010) employed the coupled MODIS and plane based hyperspectral AVIRIS data to estimate the oil plume thickness and plume geometry shape and reported plume of $17763 \mathrm{~km}^{2}$ $\left(3363 \mathrm{~km}^{2}\right.$ of thick oil) as shown in Figure 3(a) is used as a reference value. The oil plume area and geometry shape reported by Clark et al. (2010) is compared to the estimated identified thick oil spill area of $3121.35 \mathrm{~km}^{2}$ which is obtained using the proposed method.

Figure 3(b) shows that the modeling result of the estimated oil plume area of this study. Estimation of thicker oil slick areas is vital for cost-effective clean-up actions. Figure 3(b) illustrates the detected relatively thicker oil area $\left(4838.84 \mathrm{~km}^{2}\right)$ is larger than the reported thick oil area (Clark et al., 2010). Particularly, the top parts of the relatively thicker oil plume marked orange and red in Figure 3(a) and 3(b) respectively are almost identical. Moreover, results for the red circle region thicker oil plumes are estimated with an area of $3121.35 \mathrm{~km}^{2}$ (thicker oil plumes in red circle area in Figure 3(b)) compared to the thicker oil plumes marked orange at an reported area of $3363 \mathrm{~km}^{2}$ for the same red circle region in Figure 3(a). For the lower portion of 


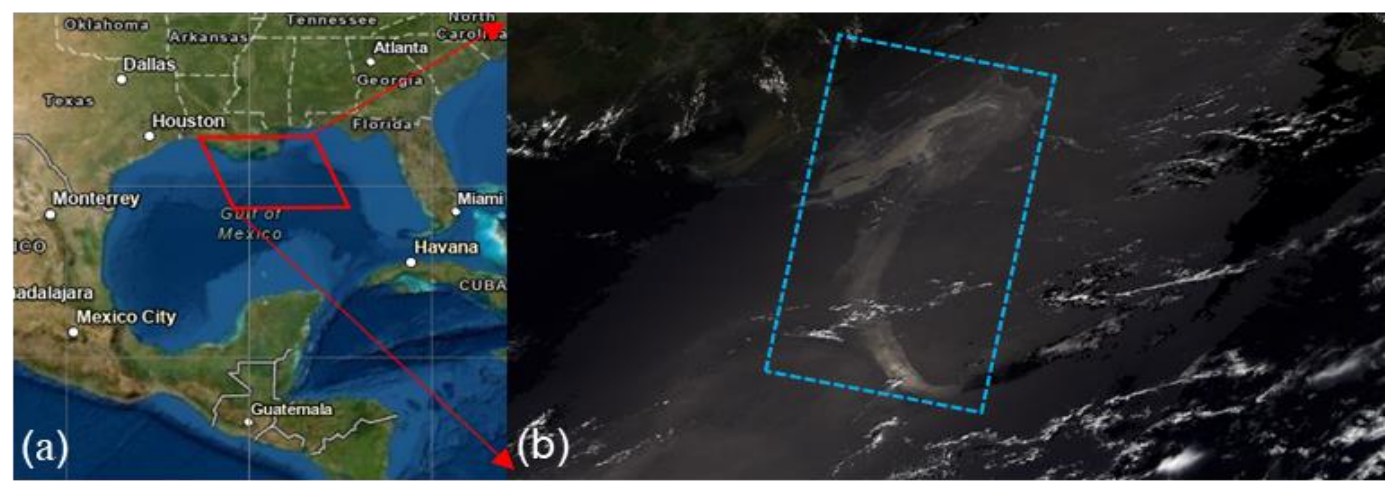

Figure 2. (a) The selected study area (red box); (b) the retrieved MODIS RGB image of the Deepwater Horizon Oil Spill (blue box is the major spill zone).
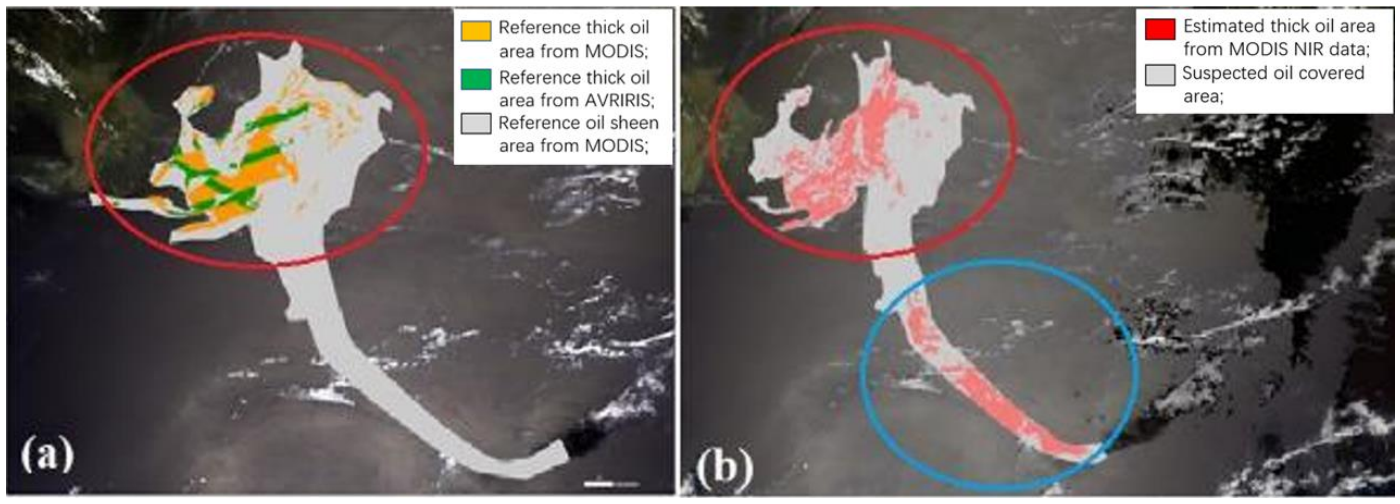

Figure 3. (a) A reported reference oil map for the same time and date (Clark et al., 2010) (Orange and green refers thick oil slick while green is the plane-instrument detected thick oil slick); (b) Corrected results of relatively clear (thicker) oil spill over oil spill area results (red is the relatively thicker oil slick).

the oil plume as indicated in the blue circle of Figure 3b, an additional area of relatively thicker oil slicks (marked red) with an estimated area of $1717.48 \mathrm{~km}^{2}$ is detected. The differences between two studies are also possibly attributed to the difference in the data processing including the consideration of band selection, cloud removal, glint contamination, and interpretation tools.

\subsubsection{Discussion}

As shown in Figure 2, there are many clouds (white pixels) over the oil plume, these clouds have higher reflectance value than water in the NIR band but in some cases similar to the oil plume when the oil plume is under glinted condition. Cloud removal is sensitive for identifying the oil-covered water area. Using alternative advanced cloud detection methods might provide better cloud removal results. Zhen (2019) developed a cloud detection algorithm for remote sensing image based on linear iterative clustering and the modified Qtsu's method to achieve improved results. Tarrio (2020) compared 5 different cloud masking methods and suggested an ensemble approach of aggregating results from multiple algorithms to remove cloud noise.

Figure 4 presents the result of cloud removal based on the cloud flag information of MODIS. As shown in Figure $4 \mathrm{~b}$ and Figure 4c, there may still have some small pieces of scattered clouds which were not completely removed using the MODIS cloud mask product. These suspected cloud pixels are identified as oil due to the similar reflectance level in the NIR band compared to oil resulting in detection errors.

Sun glinted area in the oil plume area poses another issue to affect the accuracy of estimating oil plume geometry. As some portion of the GOM oil plume is located in a glinted area, the satellite-derived result for that part of the oil area (i.e., green box area of Figure 5b) is darker than the water near the oil plume (yellow box area of Figure 5b), indicating that the glinted sea can have a higher NIR reflectance than oil in the non-glinted area.

For the above mentioned reason, if a single threshold is applied to all the analyses, water in some glinted area will be counted as oil (e.g., the yellow boxes of Figure 5) while oil in other areas in the less glinted area will be excluded (e.g., the green boxes of Figure 5). Different levels of sun glinted area are examined based on the Cox-Munk model. It gives a closer result to the reference result (Clark et al., 2010) compared to that without glint correction (Figure 5b). In summary, this study proves that MODIS band 2 NIR based oil plume detection meth- 
od is applicable with high level of accuracy, and reasonable cloud noise removal and glint correction treatment. However, this method can be additionally explored to further remove cloud noise signals and detect very thin oil sheen to process highresolution satellite data under higher computational cost with more local hydrogeological data (Hu, 2011; Pisano et al., 2015).

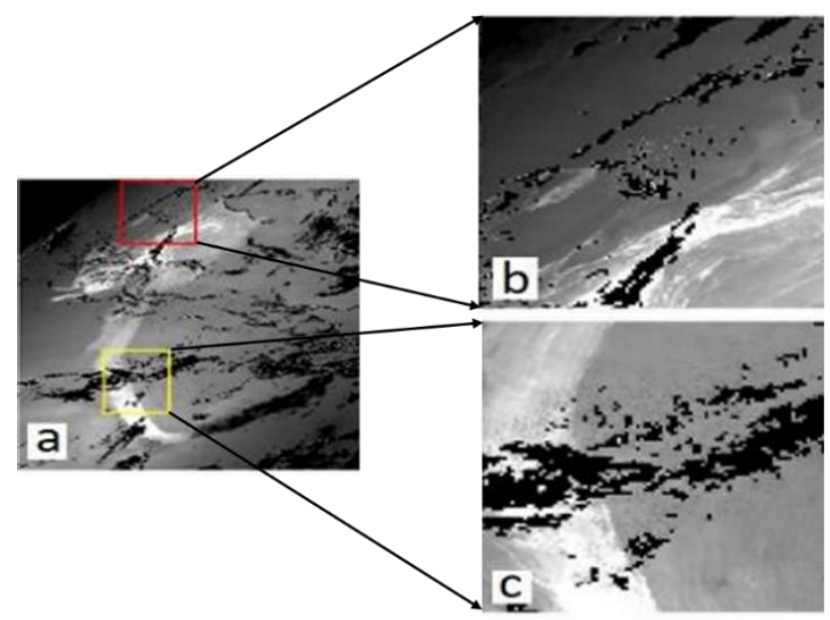

Figure 4. (a) Results of cloud removal (removed cloud pixels shown in black) of the whole area; (b) in the red box area; (c) in the yellow box area.

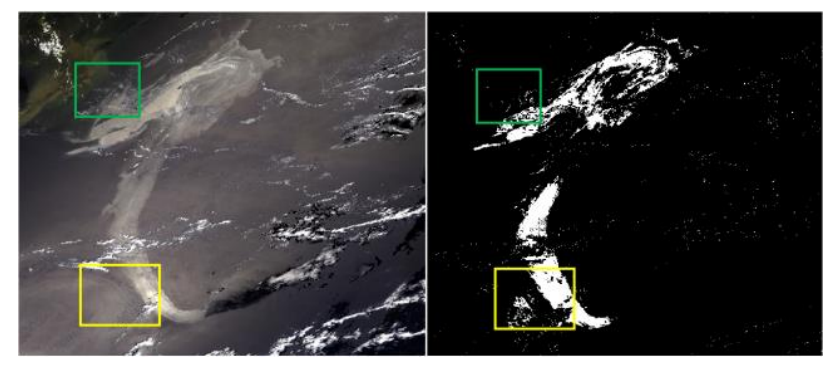

Figure 5. Illustrative results of glint effect over the studied area: (a) RGB image; (b) MODIS band 2 image after land and cloud removal using single threshold. (Area in the green box shows low glinted area and the yellow box gives high glinted area).

\subsection{Case 2: Norilsk Oil Spill}

The Norilsk oil spill occurred on 29 May 2020 in northern Russia due to the failure of a fuel storage tank, causing a large oil spill into the Ambarnaya River (TASS, 2020). This river is reported to be shallow and previously polluted by the local mining industry (Interperiodica, 1999). Due to the narrow river channel, MODIS data with $500 \mathrm{~m}$ resolution NIR bands is not suitable. Therefore, Sentinel-2 data (data source: https://scihub. copernicus.eu/dhus/) with much higher spatial resolution is extracted for the spill area (Figure 6).

Satellite data from Sentinel-2 on May 23rd, May 31st, June 8th, June 13th and June 20th in 2020 are used in this study due to heavy cloud effects during other days. Multispectral analysis gives that band $11(1610 \mathrm{~nm})$ and band $12(2190 \mathrm{~nm})$ have a reflectance spike but the spatial resolution is lower $(20 \mathrm{~m})$, while band $8(842 \mathrm{~nm})$ has a relatively high reflectance with higher spatial resolution $(10 \mathrm{~m})$ but not at the reflectance spike (Clark et al., 2010). A comparison between the images of band 8 (B8) and band 11 (B11) is presented in Figure 6. It is observed that oil is easier to be detected in the image of B8 with sharper edges as compared to the image of B11. Hence, B8 of Sentinel-2 is used for further analysis.

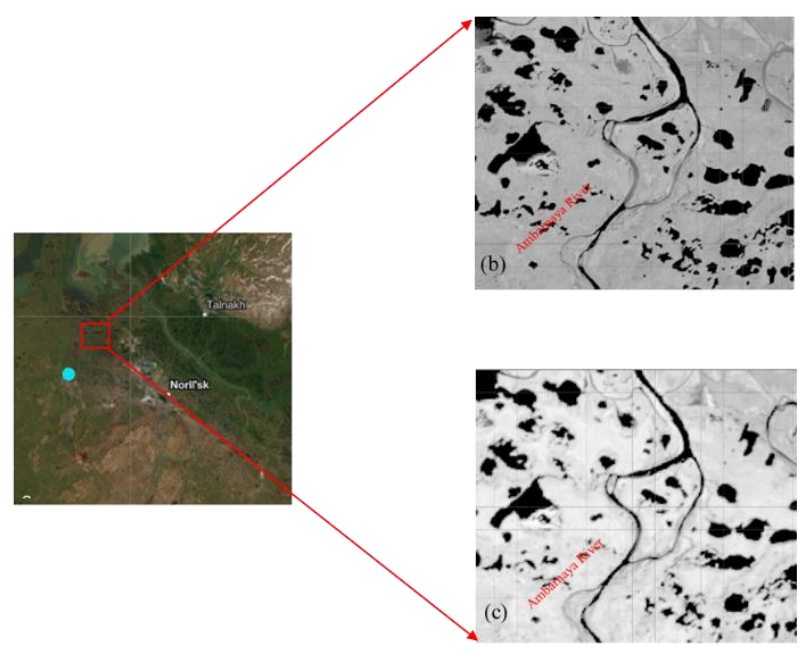

Figure 6. (a) Location of the studied area indicated in the red box (the blue dot represents the location of the oil tank facility) with results of (b) Multispectral analysis with B8 and (c) Multispectral analysis with B11 from Sentinel 2 on 31 May 2020.

\subsubsection{High-Resolution Satellite-Derived Results}

The method tested in the GOM case is applied to the Norilsk Oil Spill with a same data pretreatment analysis. However, characteristics of this area largely differ from Gulf of Mexico in terms of surface water type, scale, water quality, water depth, local climate and environmental conditions. For the noise removal process, water pixels of May 23rd, 2020 (Figure 7(j)) are set as a basis as water under oil can be screened out. Water pixels on other dates are overlaid to the basis to analyze the missing area due to spilled oil. During the oil spill period, the water bodies in the interested area are either fully covered by clouds or free of clouds, hence only cloud free images were used and cloud removal was not processed. Figure 7 presents the satellite-derived RGB image compared with the identified oil-covered area after applying the pretreatment method proposed in this study for the selected dates. Before quantification of the area of oil plume over the study site, initial results in RGB images are compared with a report from the European Space Agency (ESA) with labeled oil in the same area based on the Sentinel-2 data on May 23rd, May 31st and June 1st in 2020 (ESA, 2020). It validates that the modeling results of oil plume area size and geometry (based on Figure 7) are in line with the ESA results.

Figure 7(b) and 7(d) show that a large amount of oil exists in the middle of the study area. Also, a small proportion of oil 
(a) RGB image on $31^{\text {st }}$ May 2020

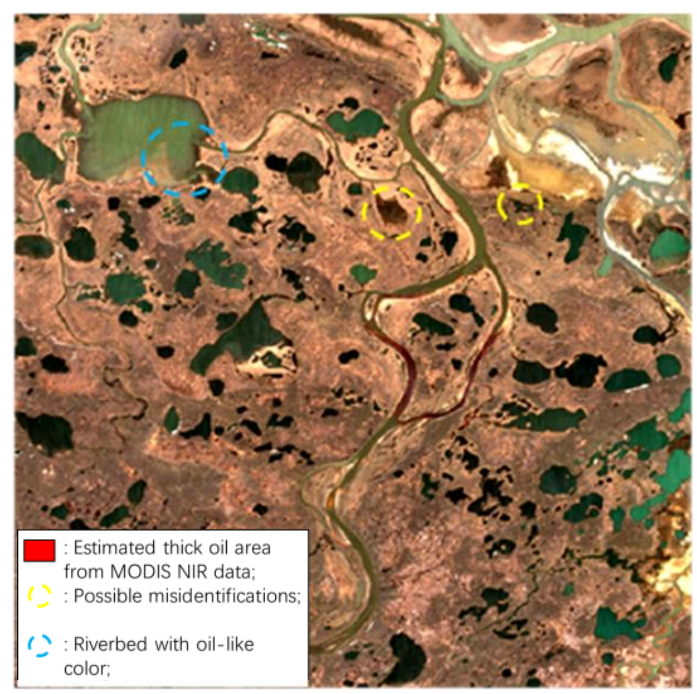

(c) RGB image on $1^{\text {st }}$ June 2020

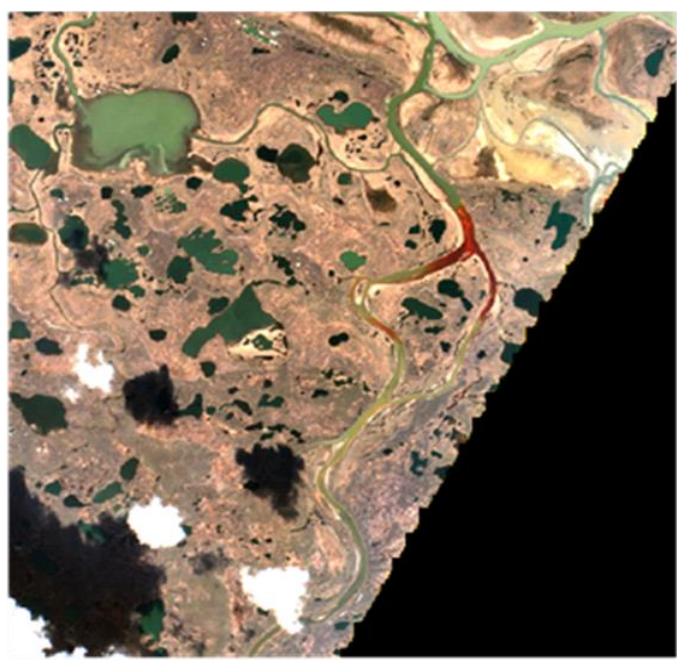

(e) RGB image on $8^{\text {th }}$ June 2020

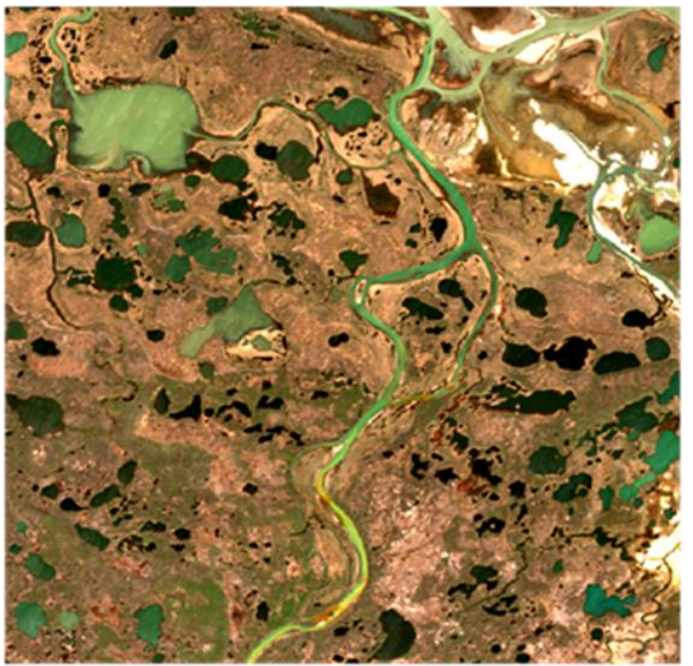

(b) Detected oil (red area) on 31 $1^{\text {st }}$ May 2020

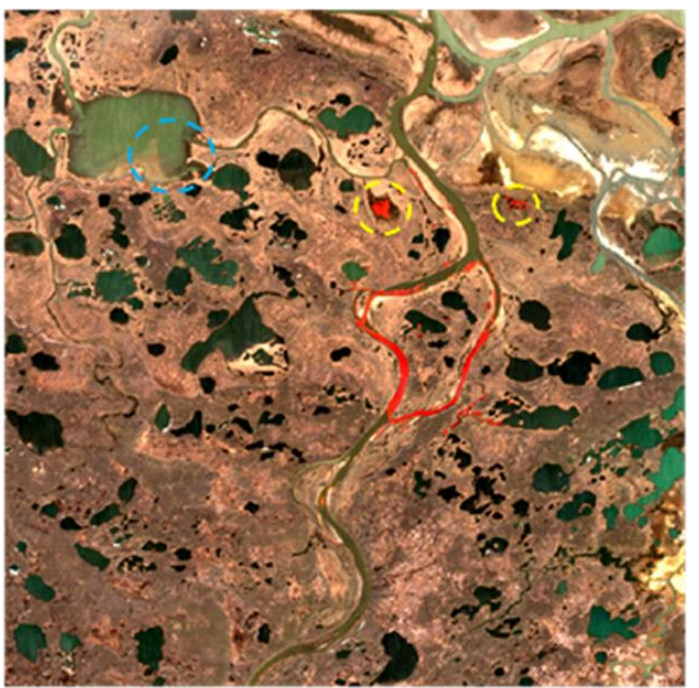

(d) Detected oil (red area) on $1^{\text {st }}$ June 2020

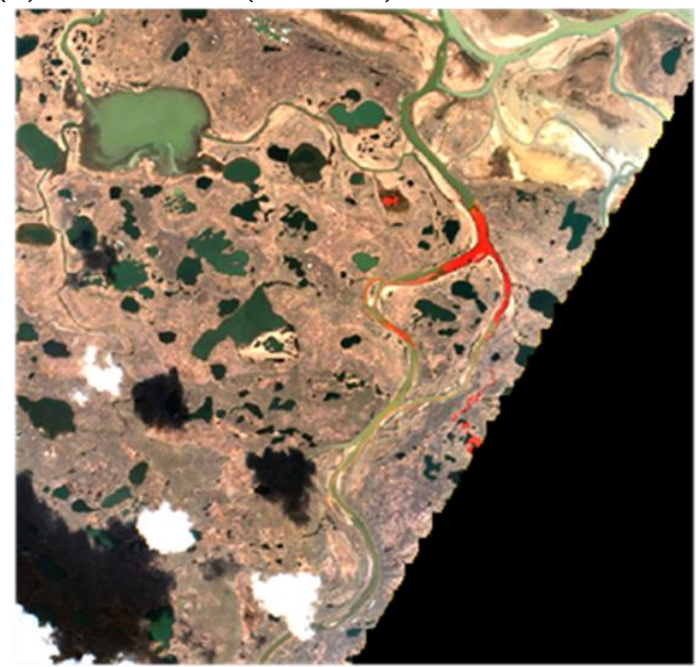

(f) Detected oil (red area) on $8^{\text {th }}$ June 2020

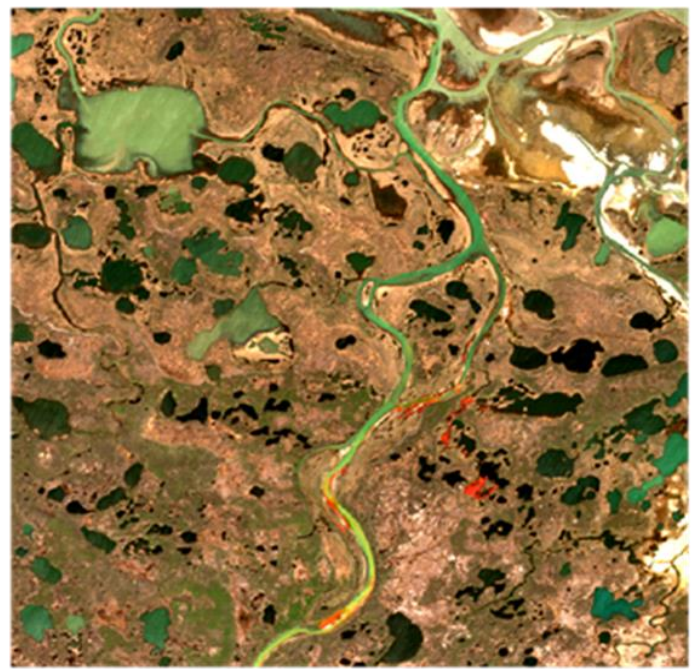


(g) RGB image on $13^{\text {rd }}$ June 2020

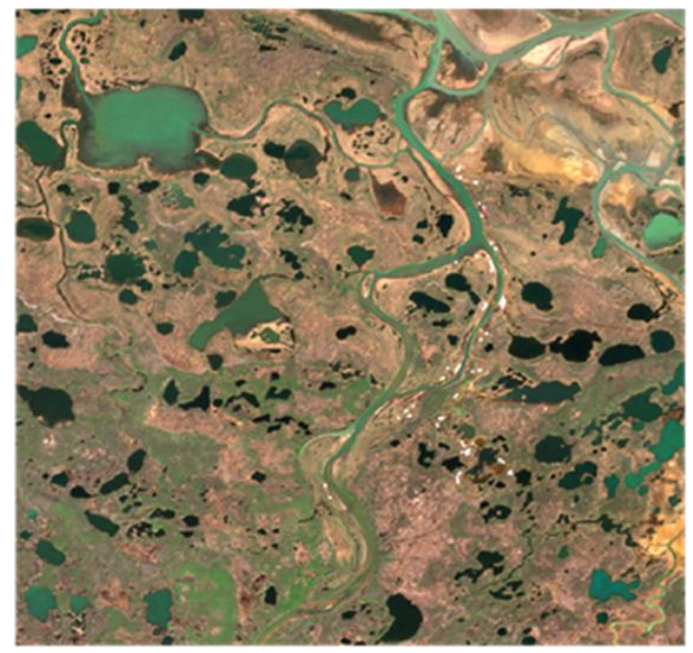

(i) RGB image on $20^{\text {th }}$ June 2020

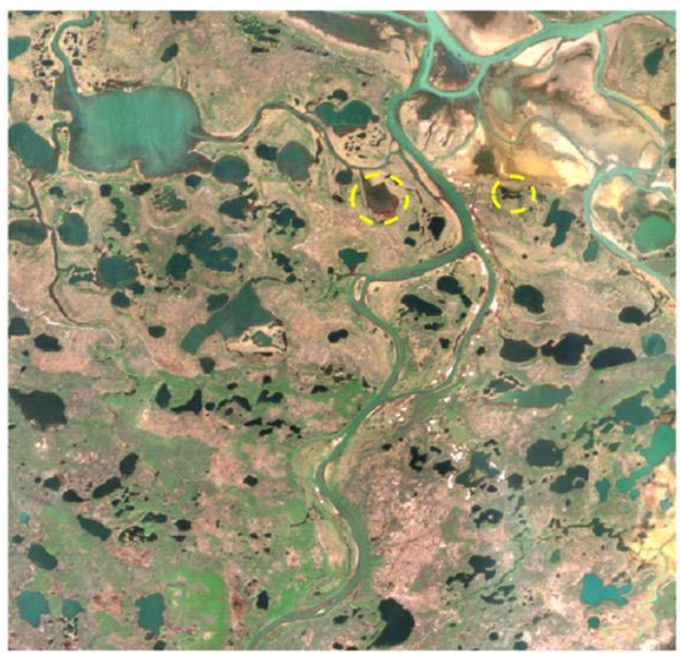

(h) Detected oil (red area) on $13^{\text {rd }}$ June 2020

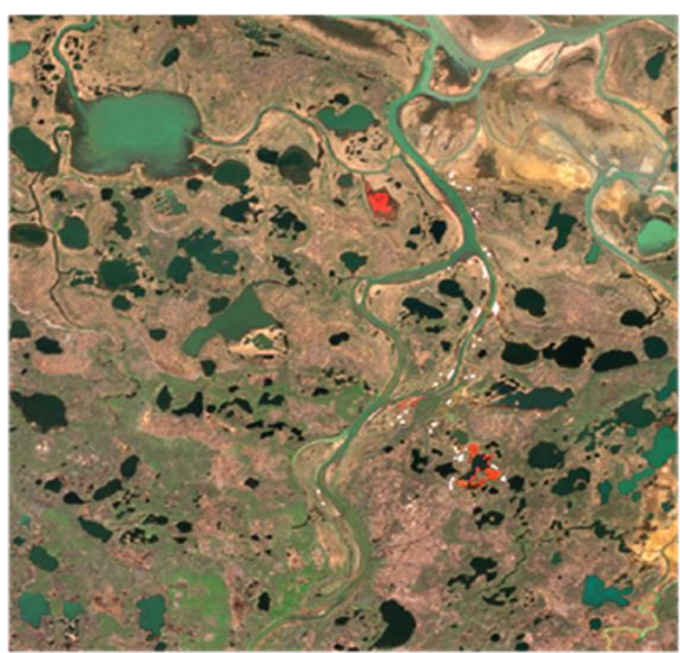

(j) RGB image of $23^{\text {rd }}$ May 2020

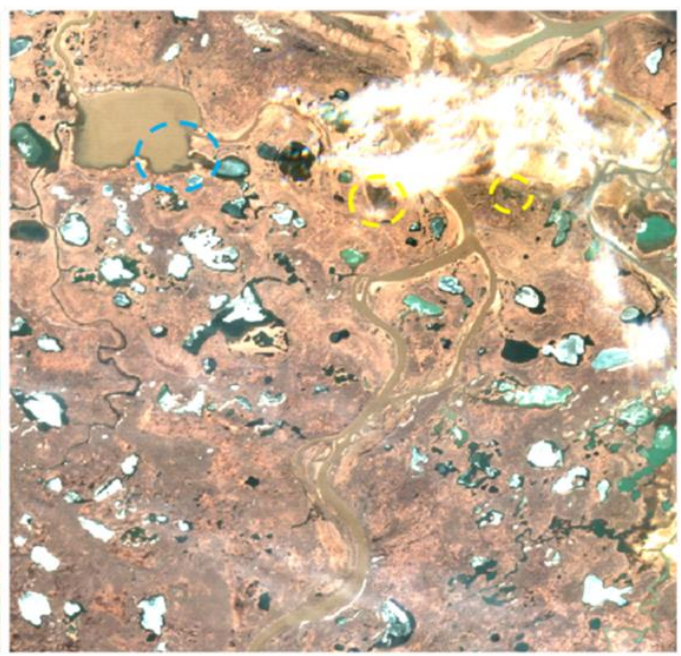

Figure 7. RGB image of case study area showing spill region on 31st May 2020, (a) without oil detection area (b) with identified oil detected area (in red); RGB image of study area showing spill region on 1st June 2020 (c) without identified oil detection area (d) with identified oil covered area ; RGB image of study area showing spill region on 8th June 2020 (e) without identified oil detection area, (f) with identified oil covered area; RGB image of study area showing spill region on 13 th June 2020 (g) without identified oil detection area, (h) with identified oil covered area; (i) RGB images of 20th June 2020; (j) RGB image of 23rd May 2020.

entered the nearby lakes through small tributaries (e.g., Figure $7(f))$. However, the two small oil plumes mapped in the top of Figure 7(b) (yellow circles might be misidentified based the following possible reasons: 1) the majority of the oil did not pass through the affected area; 2) the small oil plume marked by a yellow circle in Figure 7(a), 7(b) and 7(i) may be misidentified as the same area due to shallow water level exposing the color of the lake bed or high sediment load.

After few days, the majority of the oil plume moves further to the north on 1st June as indicated in Figure 7(d). On 8th June, the identified oil area has dispersed to the nearby river-lake water system in the bottom right area as shown in Figure 7(f). Oil distribution in Figure 7(f) is similar to the oil distribution in
Figure 7(d). Oil is not detected after 13th June, 2020 (Figure 7(f) and Figure 7(h)), which may be due to prompt cleanup actions. The satellite-derived results in this study give that the estimated area of oil coverage is $0.3149 \mathrm{~km}^{2}\left(0.2268 \mathrm{~km}^{2}\right.$ without misidentified oil area), $0.2380 \mathrm{~km}^{2}\left(0.2076 \mathrm{~km}^{2}\right.$ without misidentified oil $), 0.1617 \mathrm{~km}^{2}, 0.0963 \mathrm{~km}^{2}\left(0.0575 \mathrm{~km}^{2}\right.$ without misidentified oil) for 31st May, 1st June, 8th June and 13th June, 2020, respectively. Shapovalova (2020) reported the oil spill flowed into the local rivers after May 29th affecting an area approximately of $180,000 \mathrm{~m}^{2}$ (i.e., $0.18 \mathrm{~km}^{2}$ ). This reported affected area is very close to but smaller than our estimation on 31st May, 1st June (without misidentified oil) when the majority of the fuel was still in the scenes. 

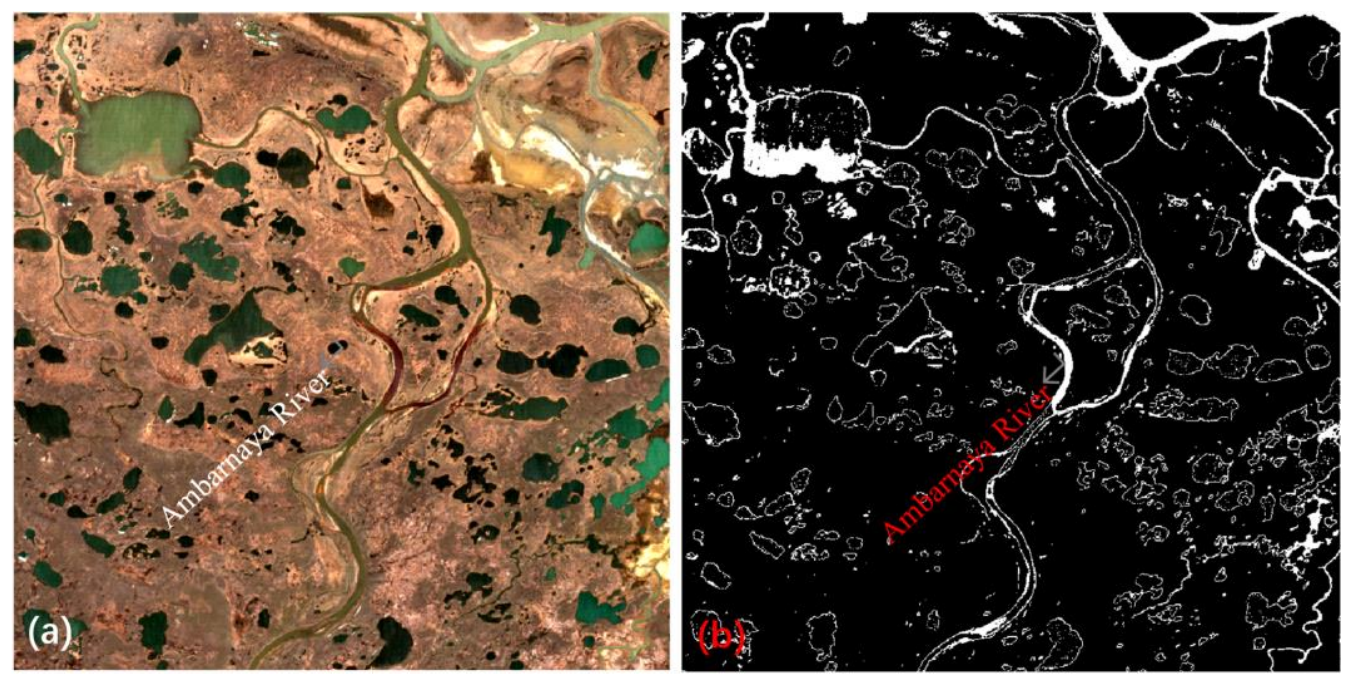

Figure 8. RGB image (a) and band 8 image of Sentinel-2 after applying land masking and NIR threshold (b) on May $31^{\text {st }}, 2020$.

\subsubsection{Discussion}

The complex nature of the Ambarnaya River leads to several challenges during this study. First, water pixels classified by the NDWI along the side of the river channel have a similar NIR reflectance level compared to oil emulsion layers, which may affect the estimation of oil plume edge. These pixels with oil-like NIR reflectance can be identified as moist soil or other non-water features due to the shallow water depth (Mondejar and Tongco, 2019). As depicted in Figure 8, many edges of the river channels and boundaries of lakes are delineated. River channels and boundaries with high humidity may be misidentified as water (Zhang et al., 2019). This issue can be handled by setting a higher threshold to the land masking process, but smalller creeks and smaller water bodies with oil may also be screened out. Another solution is employing better water extraction methods. For instance, Zhang et al. (2019) suppressed the noise and improved accuracy (like shadows, built-up areas and humid bare soil) in water extraction using the presence and background learning algorithm combining with Sentinel-2 data and OpenStreetMap data.

Image Segmenter app from the MATLAB® toolstrip has been employed to remove river edges that have similar reflectance compared to oil. The RGB image is also utilized to eliminate shallow water that does not have the dark red color of oil layers (Leifer et al., 2012).

As aforementioned, the study river is shallow. For this reason, not only the oil-free riversides can have a similar reflectance compared to oil, but this also can happen in the middle of the river or in the lakes. Exposed bedrock with higher NIR reflectance can be classified as water pixels (Herndon et al., 2020). As indicated in previous studies (Baldridge et al., 2009; Clark et al., 2010), oil can have a similar reflectance value to a range of different rocks for the related satellite band data. Thus, using the NIR band alone cannot solve this issue. Oil and oil emulsions appear dark reddish in colour both in the Gulf of Mexico case (Clark et al., 2010) and the Norilsk case (Skarbo, 2020).
Hence, the RGB image is also utilized for an indepth analysis by removing blocks that are not dark red in the RGB image. However, when they have the similar color compared to the oil (like the soil at the entrance of the lake in the top left corner of the study area, e.g., marked in blue circle in Figure 7(a)), the detection of residual oil could be a challenge. Therefore, in addition to high accuracy of quantifying oil plume area for offshore oil spills, the proposed method for shallow river case has a better level of accuracy to detect oil plume areas in the middle of the river channel where the water is deep enough such as Figure 7(b). Our results (i.e., our satellite-derived affected area of 0.2076 $\mathrm{km}^{2}$ on May 31st, 2020 compared the reported affected of 0.18 $\mathrm{km}^{2}$ on May 29th 2020) show a good agreement with the reported polluted area, confirming a satisfied field applicability of the developed method in this study. Also, more ground local details related to the oil spill coverage area data are useful to further improve the accuracy of the developed approach for oil detection in shallow inland water systems. There are three recommendations for future studies:

(1) As discussed above, water pixels and non-water pixels can be difficult to distinguish in shallow water areas (Mondejar and Tongco, 2019). Water depth of the overlapped pixels between NDWI image and the NIR image (such as shown in the result in Figure 8) could be used as the minimum water depth to further eliminate river side pixels and shallow water areas where the reflectance level can be similar to oil layers from analysis. However, due to the shallow water depth of the river (Mel'nikov et al., 1973), elimination may also exclude too many pixels and affect the analysis process.

(2) Introducing more band information can be a potential solution for distinguishing oil and bedrock. Although rocks and riverbeds can have similar reflectance compared to oil in the NIR range (Baldridge et al., 2009; Clark et al., 2010), they may behave differently in other spectrum ranges. Possible solutions include further analyzing the constituents of the bedrock, which can support distinguishing bedrock 
and oil accurately by establishing a differently behaved band despite having the same visible color.

(3) In addition to ground stationary monitoring data, other data such as topography data can be used to determine the direction of river flow and change of water depths in river systems. Therefore, satellite image color pieces, representing the upstream of the oil layers or from where oil plume cannot move through, can be removed from the oil detection results.

\section{Conclusion}

In this study, a satellite NIR-data based approach to detect oil plume has been developed. The developed method involves two major components: pre-treatment of satellite data (land removal, cloud removal and glint level calculation), and analysis of the NIR band. Two different case studies have been conducted to examine applicability of the technique. For the GOM Deepwater Horizon Oil Spill case, the estimated area and the shape of the oil plume using the developed method are close to the reference study result, and this present study contains more details regarding the thicker portions of oil plume. Cloud over the GOM case site has been successfully removed to improve the accuracy, and it confirms that cloud and glint contamination have been a challenge to estimate oil spill area and geometry. This study proves that NIR data are useful to detect oil emulsion and thick oil layers in marine environments like the Gulf of Mexico, under the in-depth considerations of uncertainties including cloud removal and glint correction for more accurate thick oil detection. The developed approach is secondly applied to the Norilsk Oil Spill for a river system. There are challenges due to the complex nature of the local Ambarnaya River system. This includes a similar reflectance level of the channel of the riversides, the shallow water bodies and the reddish riverbed compared to oil, which pose issues during the analysis. The developed method has been examined to successfully detect thick oil and oil emulsion layers in the middle of open water bodies with enough water depth. Additional ground truth data and more analyses including cloud and glint removal and geohydrological analysis could help to deliver the final precise detection results which would further support clean-up actions.

Acknowledgments. This research was supported by the Multi-Partner Research Initiative of Fisheries and Oceans Canada and the Natural Sciences and Engineering Research Council of Canada. The authors are also thankful to Dr. Edward Owens and Dr. Elliott Taylor for the helpful comments, and Dr. Sadashiva Devadiga from NASA for informative discussions on MODIS data products.

\section{References}

Acharya, T., Subedi, A. and Lee, D. (2018). Evaluation of water indices for surface water extraction in a landsat 8 scene of nepal. Sensors. 18(8), 2580. https://doi.org/10.3390/s18082580

Althawadi, J. and Hashim, M. (2019). An approach of vicarious calibration of sentinel-2 satellite multispectral image based on spectral library for mapping oil spills. 6th International Conference on Geomatics and Geospatial Technology, GGT.
Arslan, N. (2018). Assessment of oil spills using sentinel 1 c-band sar and landsat 8 multispectral sensors. Environmental Monitoring and Assessment, 190(11), 1-14. https://doi.org/10.1007/s10661-018-701 7-4

Baldridge, A., Hook, S., Grove, C. and Rivera, G. (2009). The aster spectral library version 2.0. Remote Sensing of Environment, 113(4), 711-715. https://doi.org/10.1016/j.rse.2008.11.007

Bulgarelli, B. and Djavidnia, S. (2012). On modis retrieval of oil spill spectral properties in the marine environment. IEEE Geoscience and Remote Sensing Letters. 9(3), 398-402. https://doi.org/10.1109/ LGRS.2011.2169647

Byfield, V. (1998). Optical remote sensing of oil in the marine environment. Ph.D. Dissertation, University of Southampton.

Cox, C. and Munk, W. (1954). Measurement of the roughness of the sea surface from photographs. Journal of the Optical Society of America. 44(11), 838-850. https://doi.org/10.1364/JOSA.44.00838

Du, Y., Zhang, Y., Ling, F., Wang, Q., Li, W. and Li, X., (2016). Water bodies' mapping from Sentinel-2 imagery with modified normalized difference water idex at 10-m spatial resolution produced by sharpening the swir band. Remote Sensing. 8(4). https://doi.org/10.339 $0 /$ rs8040354

ESA. (2020). Arctic Circle oil spill. https://www.esa.int/ESA_Multi media/Images/2020/06/Arctic_Circle_oil_spill.

Fingas, M. and Brown, C. (2018). A review of oil spill remote sensing. Sensors, 18(1), 91-98. https://doi.org/10.3390/s18010091

Garcia-Pineda, O., Zimmer, B., Howard, M., Pichel, W., Li, X., and MacDonald, I. (2009). Using SAR images to delineate ocean oil slicks with a texture-classifying neural network algorithm (TCNNA). Canadian Journal of Remote Sensing, 35(5), 411-421. https://doi. org/10.5589/m09-035

Gede Putra, A., Osawa, T., and Mahendra, M. (2015). Oil spill detection using MODIS data (Case study: Oil pollution at Timor Sea). Ecotrophic: Journal of Environmental Science, 6(2), 102-106.

Herndon, K., Muench, R., Cherrington, E. and Griffin, R. (2020). An assessment of surface water detection methods for water resource management in the nigerien sahel. Sensors, 20(2). https://doi.org/ $10.3390 / \mathrm{s} 20020431$

$\mathrm{Hu}, \mathrm{C}$. (2011). An empirical approach to derive modis ocean color patterns under severe sun glint: MODIS color patterns under sun glint. Geophysical Research Letters, 38(1). https://doi.org/10.1029/ 2010GL045422

Institut èkonomiki i prognozirovaniîa nauchno-tekhnicheskogo progressa. (1999). Studies on Russian Economic Development. Interperiodica Pub. PP 324.

Kolokoussis, P. and Karathanassi, V. (2018). Oil spill detection and mapping using sentinel 2 imagery. Journal of Marine Science and Engineering, 6(1). https://doi.org/10.3390/jmse6010004

Krestenitis, M., Orfanidis, G., Ioannidis, K., Avgerinakis, K., Vrochidis, S. and Kompatsiaris, I. (2019). Oil spill identification from satellite images using deep neural networks. Remote Sensing, 11(15). https://doi.org/10.3390/rs11151762

Lee, M., Park, K., Lee, H., Park, J., Kang, C. and Lee, M. (2016). Detection and dispersion of thick and film-like oil spills in a coastal bay using satellite optical images. Applied Earth Observations and Remote Sensing, 9(11), 5139-5150. https://doi.org/10.1109/JSTA RS.2016.2577597

Leifer, I., Lehr, W.J., Simecek-Beatty, D., Bradley, E., Clark, R., Dennison, P., Hu, Y.X., Matheson, S., Jones, C.E., Holt, B., Reif, M., Roberts, D.A., Svejkovsky, J., Swayze, G. and Wozencraft, J. (2012). State of the art satellite and airborne oil spill remote sensing: Application to the BP DeepWater Horizon oil spill. Remote Sensing of Environment, 124, 185-209. https://doi.org/10.1016/j.rse.2012. 03.024

Liu, S., Chi, M., Zou, Y., Samat, A., Benediktsson, J. and Plaza, A. (2017). Oil spill detection via multitemporal optical remote sensing images: A change detection perspective. IEEE Geoscience and Re- 
mote Sensing Letters, 14(3), 324-328. https://doi.org/10.1109/LGR S.2016.2639540

Mel'nikov, P., Bakulin, F., Karpov, E. and Kolesov, A. (1973). Geocryological conditions and procedures for laying the Noril'sk-Messoyakha pipeline. Permafrost: Second International Conference, 599.

Mermelstein, M., Shettle, E., Takken, E. and Priest, R. (1994). Infrared radiance and solar glint at the ocean-sky horizon. Applied Optics, 33, 6022-6034. https://doi.org/10.1364/AO.33.006022

Mondejar, J. and Tongco, A. (2019). Near infrared band of landsat 8 as water index: A case study around Cordova and Lapu-Lapu city, cebu, philippines. Sustainable Environment Research, 29(1), 1-15. https://doi.org/10.1186/s42834-019-0016-5

NASA. MODIS Design: https://modis.gsfc.nasa.gov/about/design.php (accessed August 14, 2020).

National Public Radio, Inc. (2020) The oil spill from Russian nickel mine is moving towards the Arctic Ocean. http://www.npr.org/ templates/transcript/transcript.php?storyId $=878852931$

Nielson, K., Woodman, S. and Rood, S. (2020). Prospective impacts of oil spills on floodplain vegetation: Both crude oil and diluted bitumen increase foliar temperatures, senescence and abscission in three cottonwood (Populus) species. PLOS ONE, 15(3), 1-17. https: //doi.org/10.1371/journal.pone.0230630

Pisano, A., Bignami, F. and Santoleri, R. (2015). Oil spill detection in glint-contaminated near-infrared modis imagery. Remote Sensing, 7(1), 1112-1134. https://doi.org/10.3390/rs70101112

Roger, J., Vermote, E. and Ray, J. (2015) MODIS surface reflectance user's guide. https://landweb.modaps.eosdis.nasa.gov/QA_WWW/ forPage/user_guide/MOD09_UserGuide_v1.4.pdf.

Shapovalova, D. (2020). Oil spill in Siberia: Are we prepared for permafrost thaw? https://www.thearcticinstitute.org/oil-spill-siberiaprepared-permafrost-thaw/ (accessed January 9, 2021).

Shaw, J. and Chumside, J. (1997). Scanning-laser glint measurements of sea-surface slope statistics. Applied Optics, 36(18), 4202-4213. https://doi.org/10.1364/AO.36.004202

Skarbo, S. (2020) State of emergency in Norilsk after 20,000 tons of diesel leaks into Arctic river system. siberiantimes.com.

Sun, S. and Hu, C. (2019). The challenges of interpreting oil-water spatial and spectral contrasts for the estimation of oil thickness: Examples from satellite and airborne measurements of the deepwater horizon oil spill. IEEE Transactions on Geoscience and Remote Sensing, 57(5), 2643-2658. https://doi.org/10.1109/TGRS.20 18.2876091

Tarrio, K., Tang, X., Masek, J. G., Claverie, M., Ju, J., Qiu, S., Zhu, Z. and Woodcock, C. E. (2020). Comparison of cloud detection algorithms for sentinel-2 imagery. Science of Remote Sensing, 2. https:// doi.org/10.1016/j.srs.2020.100010

TASS. (2020). Diesel fuel spill in Norilsk in Russia's Arctic contained. https://tass.com/emergencies/1164423\#: :text=Cleanup\%20worke rs $\% 20$ have $\% 20$ contained $\% 20$ the,collected $\% 2 \mathrm{C} \% 22 \% 20$ the $\% 20 \mathrm{mi}$ nistry\%20said.

Topp, S., Pavelsky, T., Jensen, D., Simard, M. and Ross, M. (2020). Research trends in the use of remote sensing for inland water quality science: Moving towards multidisciplinary applications. Water, 12(11). https://doi.org/10.3390/w12010169

USGS (2010). A method for qualitative mapping of thick oil spills using imaging spectroscopy. U.S. Geological Survey Open-File Report 2010-1101.

Wu, J. (1972). Sea-surface slope and equilibrium wind-wave spectra. The Physics of Fluids, 15(5), 741-747. https://doi.org/10.1063/1.16 93978

Zhang, H. and Wang, M. (2010). Evaluation of sun glint models using MODIS measurements. Journal of Quantitative Spectroscopy and Radiative Transfer, 111(3), 492-506. https://doi.org/10.1016/j.jqsrt. 2009.10.001

Zhang, Z., Zhang, X., Jiang, X., Xin, Q., Ao, Z., Zuo, Q. and Chen, L. (2019). Automated surface water extraction combining sentinel-2 imagery and openstreetmap using presence and background learning (pbl) algorithm. IEEE Journal of Selected Topics in Applied Earth Observations and Remote Sensing, 12(10), 3784-3798. https://doi. org/10.1109/JSTARS.2019.2936406

Li, Z., Zhao, B., Tang, L., Wang, W. and Zhao, B. (2019). A robust ragged cloud detection algorithm for remote sensing image. The Journal of Engineering, 2019(21), 7640-7643. https://doi.org/10. 1049/joe.2019.0514 